\title{
Article \\ Changes in Lifestyle and Dietary Habits during COVID-19 Lockdown in Italy: Results of an Online Survey
}

\author{
Melania Prete ${ }^{1}\left(\mathbb{D}\right.$, Anna Luzzetti ${ }^{2}$, Livia S. A. Augustin ${ }^{3, * \mathbb{D}}$, Giuseppe Porciello $^{3}\left(\mathbb{D}\right.$, Concetta Montagnese ${ }^{3, *(\mathbb{D})}$, \\ Ilaria Calabrese ${ }^{4}$ (D), Giada Ballarin ${ }^{5}$, Sergio Coluccia ${ }^{3}$, Linia Patel ${ }^{1}$, Sara Vitale ${ }^{3}$, Elvira Palumbo ${ }^{3}$, \\ Egidio Celentano $^{3}$, Carlo La Vecchia ${ }^{1}$ (D) and Anna Crispo ${ }^{3}$ (D)
}

check for updates

Citation: Prete, M.; Luzzetti, A.; Augustin, L.S.A.; Porciello, G.; Montagnese, C.; Calabrese, I.; Ballarin, G.; Coluccia, S.; Patel, L.; Vitale, S.; et al. Changes in Lifestyle and Dietary Habits during COVID-19 Lockdown in Italy: Results of an Online Survey. Nutrients 2021, 13, 1923. https://doi.org/10.3390/ nu13061923

Academic Editor: Maria D. Mesa

Received: 26 April 2021

Accepted: 31 May 2021

Published: 3 June 2021

Publisher's Note: MDPI stays neutral with regard to jurisdictional claims in published maps and institutional affiliations.

Copyright: (c) 2021 by the authors. Licensee MDPI, Basel, Switzerland. This article is an open access article distributed under the terms and conditions of the Creative Commons Attribution (CC BY) license (https:/ / creativecommons.org/licenses/by/ $4.0 /)$.
1 Department of Clinical Science and Community Health, Università degli Studi di Milano, 20122 Milan, MI, Italy; melania.prete.1@hotmail.it (M.P.); linia.patel@unimi.it (L.P.); carlo.lavecchia@unimi.it (C.L.V.)

2 CEINGE Advanced Biotechnologies, University of Naples Federico II, Via S. Pansini 5, 80131 Naples, NA, Italy; annaluzzetti@gmail.com

3 Epidemiology and Biostatistics Unit, Istituto Nazionale Tumori-IRCCS “Fondazione G. Pascale”, via M. Semmola 1, 80131 Naples, NA, Italy; g.porciello@istitutotumori.na.it (G.P.); sergio.coluccia@hotmail.it (S.C.); s.vitale@istitutotumori.na.it (S.V.); elvirapalumbo41@gmail.com (E.P.); e.celentano@istitutotumori.na.it (E.C.); a.crispo@istitutotumori.na.it (A.C.)

4 Department of Clinical Medicine and Surgery, Federico II University, Via S. Pansini 5, 80131 Naples, NA, Italy; ilariacalabrese@live.it

5 Department of Movement Sciences and Wellbeing, Parthenope University, Via F. Acton 38, 80133 Naples, NA, Italy; giadaballarin@outlook.it

* Correspondence: l.augustin@istitutotumori.na.it (L.S.A.A.); c.montagnese@istitutotumori.na.it (C.M.)

\begin{abstract}
COVID-19 is an unprecedented global pandemic. On 12 March 2020, a lockdown order was issued in Italy in attempt to contain the health crisis. The study aimed to assess the impact of the COVID-19 lockdown on diet, physical activity, sleep quality, and distress in an Italian cohort. An online anonymous interview, which included validated questionnaires was created to compare lifestyle habits pre- and during the lockdown. Data analysis from 604 subjects with a mean age of 29.8 years was carried out using multivariate analysis. Compared to pre-COVID-19 times, 67\% of people changed their eating habits and increased consumption of foods containing added sugars. Women and men with low adherence to the Mediterranean Diet (MedDiet) were more likely to be physically inactive $(p<0.0001$ and $p<0.01$, respectively). Results from logistic regression showed a three times higher risk of being inactive if adherence to the MedDiet was low $(p<0.0001)$, especially in men between 26 and 35 years. Lower levels of distress were reported in males who were physically active $(89 \%)(p<0.001)$. Our findings may help to identify effective lifestyle interventions during restrictive conditions.
\end{abstract}

Keywords: COVID-19; lifestyle; Mediterranean diet; physical activity; sleep quality; distress

\section{Introduction}

The outbreak of COVID-19 in Italy started on 21 February 2020, with 16 confirmed cases in the town of Codogno in the Lombardy region. This number increased to 60 after only $24 \mathrm{~h}$ and the first deaths were reported on the same day. When the epidemic spread to several Italian regions, a total lockdown of the country was declared on March the 12th. Schools and most businesses were closed and guidelines for home confinement were issued (Phase 1). These restrictions severely limited movement and interaction of people. Regulations issued within this time only permitted movement for reasons of necessity (i.e., grocery shopping) or for medical reasons. The end of Phase 1 (on May 4) marked the beginning of Phase 2, which allowed people to leave their homes and reunite with distant family members. 
The consequences of such prolonged restrictions on the population were mixed [1,2]: the aim was to reduce the spread of the infection and mortality from COVID-19 disease, however they also brought about a sudden change in people's lives with possible consequences on the health and well-being of the community. Understanding the lifestyle implications of the measures introduced to reduce COVID-19 infections may help in making well-informed decisions on the best strategies to adopt in similar future scenarios [3].

Several studies from different countries (Italy, Spain, and Canada) evaluated the possible lifestyle changes during COVID-19 lockdown [4-11]. Data from two Italian studies suggest that a large part of the population did not follow healthy eating habits [8] and that there was a significant reduction in habitual physical activity [9] while others found improvements in diet quality in young people $[6,10,11]$. Anxiety or boredom may modify nutritional choices, leading to prefer "comfort foods" rich in sugars, which cause a temporary increase in serotonin levels with a positive effect on mood and stress reduction [12-15]. In this regard, it is important to underline that domestic confinement, by influencing the stress and anxiety levels in the general population [16] may consequently influence food choices and the level of physical activity. A poor quality diet in turn may reduce body defenses against disease $[17,18]$.

Therefore, we investigated lifestyle habits in subjects who responded to an online survey with the aim of evaluating the impact of COVID-19 lockdown on different aspects of lifestyle (diet, physical activity, sleep quality, and distress) in young Italian adults who responded to an online survey.

\section{Materials and Methods}

An online literature search was conducted, including PubMed, Embase, and Web of Science, to search for validated questionnaires suitable for this investigation.

Four validated questionnaires were selected to evaluate different aspects of lifestyle: diet, physical activity (PA), sleep quality, and distress. The use of these questionnaires in other studies was also considered to warrant increased validity and reliability. Details of all questionnaires are reported in the Supplementary Table S1. All questionnaires were collected in a single interview, created using the Google survey tool. The interview included a total of 65 items: 5 relating to socio-demographic characteristics, 32 relating to diet and diet changes compared to the period before the lockdown, 9 relating to PA and PA changes, 11 relating to quality of sleep and its changes, 6 related to distress and its changes, and 2 questions related to the comprehension of the interview (Table S1). Participants were recruited via social media (Facebook, WhatsApp, and Instagram). Inclusion criteria included the ability to use social media, being a resident of Italy during the lockdown, and understanding more than $75 \%$ of the interview. If all these three criteria were not met, the participants were excluded.

A total of 612 individuals participated in the survey, however two were excluded because they were not a resident in Italy, four subjects because of difficulties in understanding the questionnaire to measure the Mediterranean Diet (QueMD), and two subjects because they reported $<75 \%$ understanding of the tests. Complete data from 604 participants were used for these analyses. Data was collected a month into Phase 1 lockdown (22 April to 3 May 2020). No ethic approval or informed consent was required given the nature of the study (online survey) and that data were anonymously collected on a voluntary basis.

\subsection{Diet}

The short self-managed 15-item questionnaire QueMD was used to assess eating habits [19]. QueMD allows the frequency of the consumption of nine foods usually considered key components of the Mediterranean Diet (MedDiet), namely vegetables, olive oil, dried fruits (nuts, almond, hazelnuts), whole grains, legumes, wine, fish products, and fresh fruits to be calculated. In addition to these nine items there were other items related to the consumption of dairy products (milk and yogurt), red and processed meat, sweets and fats (butter, margarine, cooking cream) and sugary drinks. For each food items, responders 
could choose between five consumption levels ranging from "never or rarely" to high frequency [19]. QueMD score is based on a modified version of the method proposed by Trichopoulou et al. [20] which assigns 1 point to the consumption of the following portions of: vegetables $\geq 2$ /day, fresh fruit $\geq 2$ /day, dried fruit $\geq 2$ /week, whole grains $\geq 1$ /day, legumes $\geq 2$ /week), fish $\geq 2$ /week, and olive oil $\geq 3$ tablespoons/day, red and processed meat $\leq 3 /$ week and 1 point for drinking 1 or 2 glasses of wine per day for men or $>0<1 /$ day for women. The sum of the points obtained results in the final score ranging from 0 (lowest adherence to MedDiet) to 9 (highest adherence to MedDiet).

\subsection{Physical Activity}

To assess physical activity the International Physical Activity Questionnaire (IPAQ) a short form was used: seven items including intensity of activity (e.g., vigorous vs. moderate), the time spent walking in the last seven days, and the time spent sitting [21]. To calculate the score, the Metabolic equivalent task (METs) of the various activities were calculated as: (i) number of days in which vigorous physical activity took place $\mathrm{x}$ minutes spent on vigorous activity $\times 8$; (ii) number of days during which moderate physical activity took place $x$ minutes spent on moderate activity $x 4$; (iii) number of days walked $x$ minutes spent walking x 3.3. Total METs were calculated as the sum of Walking, Moderate, and Vigorous MET scores. If total METs were $\leq 700$, the subject was classified as inactive, for scores between 700 and 2519 the subject was classified as moderately active, and for score $\geq 2520$ the subject was classified as active.

\subsection{Distress}

Distress was measured using the six-item Kessler psychological distress scale (K6) [22], which was used for an investigation on the effects of social distancing in China [3]. This questionnaire includes six questions about a person's emotional state. Each item is scored from 0 (never) to 4 (all the time). Adding the scores of the 6 items, a minimum score of 0 and a maximum score of 24 is obtained. Scores $\leq 8$ indicate no distress, scores between 9 and 16 indicate moderate distress, and scores $\geq 17$ indicate high distress.

\subsection{Sleep Quality}

Sleep quality was investigated with the Pittsburgh Sleep Quality Index (PSQI) [23], which includes 19 questions grouped into 9 items. To calculate the PSQI score, the 9 items were processed to obtain 7 component scores, each of which has a value from 0 (no difficulty) to 3 (serious difficulty). The 7 scores obtained are then added together to obtain the total score that falls in a range from 0 to 21. A lower total score corresponds to better sleep quality.

\subsection{Data Analysis}

The characteristics of subjects are described as number $(n)$ and percentage (\%). For each questionnaire, we compared data by gender and by levels of MedDiet adherence, physical activity, sleep quality, and distress. Student t-test was used to compare continuous variable and Chi-square test was used to compared categorical variables. Multivariate logistic regression analysis was used to investigate the association between MedDiet adherence and physical activity. Results were considered statistically significant at a $p$-value $<0.05$. The $\mathrm{R}$ software was used for all data analysis.

\section{Results}

Participants were aged between 16 and 62 years (mean age 29.8 years), 72\% were women, $79 \%$ were unmarried, $43 \%$ were students and $82 \%$ were residents of southern Italy (Table 1). 
Table 1. General characteristics of the study participants in the total subjects and by sex.

\begin{tabular}{|c|c|c|c|c|c|c|c|}
\hline & \multicolumn{2}{|c|}{$\begin{array}{l}\text { Women } \\
n=433\end{array}$} & \multicolumn{2}{|c|}{$\begin{array}{c}\text { Men } \\
n=171\end{array}$} & \multicolumn{2}{|c|}{$\begin{array}{c}\text { Total } \\
n=604\end{array}$} & \multirow[t]{2}{*}{$p^{*}$} \\
\hline & Mean & SD & Mean & SD & Mean & SD & \\
\hline \multirow[t]{2}{*}{ Age } & 29.7 & \pm 10.2 & 30.1 & \pm 11.0 & 29.8 & \pm 10.4 & $0.65^{\dagger}$ \\
\hline & $n$ & $(\%)$ & $n$ & $(\%)$ & $N$ & $(\%)$ & \\
\hline \multicolumn{8}{|l|}{ Age group } \\
\hline$<26$ & 200 & 46.2 & 73 & 42.7 & 273 & 45.2 & 0.51 \\
\hline $26-35$ & 147 & 33.9 & 57 & 33.3 & 204 & 33.8 & \\
\hline$>35$ & 86 & 19.9 & 41 & 23.9 & 127 & 21.0 & \\
\hline Total & 433 & 100 & 171 & 100 & 604 & 100 & \\
\hline \multicolumn{8}{|l|}{ Marital Status } \\
\hline Unmarried & 341 & 78.8 & 134 & 78.4 & 475 & 78.6 & 0.96 \\
\hline Married & 18 & 4.2 & 8 & 4.7 & 26 & 4.3 & \\
\hline Divorced/Widow & 74 & 17.1 & 29 & 16.9 & 103 & 17.1 & \\
\hline Total & 433 & 100 & 171 & 100 & 604 & 100 & \\
\hline \multicolumn{8}{|l|}{ Occupation } \\
\hline Students & 192 & 44.3 & 68 & 39.8 & 260 & 43.1 & 0.53 \\
\hline Workers & 141 & 32.6 & 63 & 36.8 & 204 & 33.8 & \\
\hline Other & 100 & 23.1 & 40 & 23.4 & 140 & 23.2 & \\
\hline Total & 433 & 100 & 171 & 100 & 604 & 100 & \\
\hline \multicolumn{8}{|l|}{ Area of residence } \\
\hline South & 364 & 84.0 & 131 & 76.6 & 495 & 81.5 & 0.09 \\
\hline Center/North & 69 & 15.9 & 40 & 23.4 & 109 & 18.1 & \\
\hline Total & 433 & 100 & 171 & 100 & 604 & 100 & \\
\hline
\end{tabular}

* Chi-square test for categorical variables and ${ }^{\dagger}$ Student's $t$ test for continuous variables for difference between men and women; $\mathrm{SD}=$ standard deviation.

Table 2 shows that during the lockdown $63 \%(n=381)$ of participants showed low adherence to the MedDiet, $61 \%$ of women and $68 \%$ of men (Table 2). In addition, $67 \%$ $(n=406)$ of participants reported changes in their eating habits compared to the period before the lockdown.

A detailed analysis of the individual responses of the QueMD (data not shown) indicated that $37 \%$ reported consumption of at least 2 portions of vegetables per day, $8.1 \%$ consumed 3-4 tablespoons of olive oil per day, $24.5 \%$ consumed at least 2 portions of fresh fruit daily, $12 \%$ consumed dried fruit (nuts, almond, peanuts) more than 4 times/week, and $71 \%$ reported legume consumption at least twice a week. Dietary changes during the lockdown (data not shown) indicated the following: increased consumption of sweets, cakes and pastry products was reported by $51 \%$ of participants and reduced consumption of dried fruit by $73 \%$ of participants. The majority ( $>64 \%$ of participants) reported no change in the consumption of olive oil, butter, fish, red and white meat, while $55 \%$ reported no change in the consumption of bread/pasta/rice (30\% indicated increases), fresh fruit ( $28 \%$ indicated increases), and vegetables (27\% indicated increases).

Metabolic equivalents (METs) were calculated from the IPAQ-SF questionnaire. This allowed to divide subjects into three categories: 1$)$ active $(20 \% ; n=119) ; 2)$ moderately active $(41 \% ; n=248)$; inactive $(39 \% ; n=237)$ (Table 2). Forty-one percent of the women and $41 \%$ of the men resulted moderately active (Table 2). Five hundred and twenty participants $(86 \%)$ reported that their level of PA had changed compared to the period before the lockdown, specifically, $72 \%(n=434)$ claimed to be more sedentary (Table 2$)$.

A preliminary analysis of the responses to questionnaire $\mathrm{K} 6$ on distress found moderate distress in 37\% $(n=226)$ of participants and high distress in $27 \%(n=162)$ (Table 2). Among women, $42 \%$ showed moderate distress and $29 \%$ showed high distress. The percentage of men who reported distress was lower than in women (moderate distress $=25 \%$; high distress $=21 \%$ ). Compared to pre-Covid times, among 324 subjects who reported distress, $54 \%$ also reported feeling this way a little more often than usual, while $33 \%$ reported feeling it much more often than usual (Table 2). 
Table 2. Distribution of responses for diet, physical activity, distress, and quality of sleep and perceived changes, in the total subjects and by sex.

\begin{tabular}{|c|c|c|c|c|c|c|}
\hline & \multicolumn{2}{|c|}{$\begin{array}{l}\text { Women } \\
n=433\end{array}$} & \multicolumn{2}{|c|}{$\begin{array}{c}\text { Men } \\
n=171\end{array}$} & \multicolumn{2}{|c|}{$\begin{array}{l}\text { Total } \\
n=604\end{array}$} \\
\hline & $n$ & $(\%)$ & $n$ & $(\%)$ & $n$ & $(\%)$ \\
\hline \multicolumn{7}{|l|}{ Diet adherence $^{a}$} \\
\hline Low & 264 & 61.0 & 117 & 68.4 & 381 & 63.1 \\
\hline High & 169 & 39.0 & 54 & 31.6 & 223 & 36.9 \\
\hline Total & 433 & 100.0 & 171 & 100.0 & 604 & 100.0 \\
\hline \multicolumn{7}{|l|}{ Self-reported dietary changes } \\
\hline No & 134 & 31.0 & 63 & 36.8 & 197 & 32.7 \\
\hline Yes & 298 & 69.0 & 108 & 63.2 & 406 & 67.3 \\
\hline \multicolumn{7}{|l|}{ Dietary changes } \\
\hline Reduced & 174 & 40.2 & 70 & 40.9 & 244 & 40.4 \\
\hline No change & 118 & 27.3 & 41 & 24.0 & 159 & 26.3 \\
\hline Increased & 141 & 32.6 & 60 & 35.1 & 201 & 33.3 \\
\hline \multicolumn{7}{|l|}{ Physical activity ${ }^{b}$} \\
\hline Active & 81 & 18.7 & 38 & 22.2 & 119 & 19.7 \\
\hline Moderately active & 178 & 41.1 & 70 & 40.9 & 248 & 41.1 \\
\hline Inactive & 174 & 40.2 & 63 & 36.8 & 237 & 39.2 \\
\hline Total & 433 & 100.0 & 171 & 100.0 & 604 & 100.0 \\
\hline \multicolumn{7}{|l|}{ Physical activity changes } \\
\hline No change & 65 & 15.0 & 17 & 9.9 & 82 & 13.6 \\
\hline Less sedentary & 70 & 16.2 & 16 & 9.4 & 86 & 14.2 \\
\hline More sedentary & 298 & 68.8 & 138 & 80.7 & 436 & 72.2 \\
\hline \multicolumn{7}{|l|}{ Distress $^{c}$} \\
\hline Low & 124 & 28.6 & 92 & 53.8 & 216 & 35.8 \\
\hline Medium & 183 & 42.3 & 43 & 25.1 & 226 & 37.4 \\
\hline High & 126 & 29.1 & 36 & 21.1 & 162 & 26.8 \\
\hline Total & 433 & 100.0 & 171 & 100.0 & 604 & 100.0 \\
\hline \multicolumn{7}{|l|}{ Distress changes } \\
\hline As usual & 94 & 21.7 & 60 & 35.1 & 154 & 25.5 \\
\hline Much less than usual & 31 & 7.2 & 24 & 14.0 & 55 & 9.1 \\
\hline Much more than usual & 88 & 20.3 & 24 & 14.0 & 112 & 18.5 \\
\hline A little less than usual & 15 & 3.5 & 3 & 1.8 & 18 & 3.0 \\
\hline $\begin{array}{l}\text { A little more than usual } \\
\text { Sleep quality }\end{array}$ & \multicolumn{5}{|c|}{ Sleep quality ${ }^{d}$} & 43.9 \\
\hline Low & 278 & 64.2 & 92 & 53.8 & 370 & 61.3 \\
\hline High & 155 & 35.8 & 79 & 46.2 & 234 & 38.7 \\
\hline Total & 433 & 100.0 & 171 & 100.0 & 604 & 100.0 \\
\hline \multicolumn{7}{|l|}{ Sleep quality changes } \\
\hline No changes & 103 & 23.8 & 55 & 32.2 & 158 & 26.2 \\
\hline Sleep more & 87 & 20.1 & 34 & 19.9 & 121 & 20.0 \\
\hline Sleep better & 14 & 3.2 & 12 & 7.0 & 26 & 4.3 \\
\hline Sleep less & 56 & 12.9 & 18 & 10.5 & 74 & 12.3 \\
\hline Sleep worse & 174 & 40.0 & 52 & 30.4 & 225 & 37.3 \\
\hline
\end{tabular}

a Adherence to the Mediterranean diet: low adherence score $\leq 5$; high adherence score $>5$. ${ }^{b}$ Physical activity level: Inactive total METs $\leq 700$; Moderately active total METs 701-2519; Active total METs $\geq 2520$. $^{\mathrm{c}}$ Distress level: no distress score $\leq 8$; Moderate distress score 9-16; distress score $\geq 17$. ${ }^{\mathrm{d}}$ Sleep quality level: low sleep quality score $>10$; high sleep quality score $\leq 10$.

Regarding sleep quality, the PSQI showed that $61 \%(n=370)$ of participants had low sleep quality, especially among women (64\%) (Table 2). Compared to the period before lockdown, half reported less sleep or lower quality of sleep (Table 2).

Table 3 shows the distribution of responses for levels of adherence to the MedDiet, physical activity, distress, and sleep quality. Both women and men with low adherence to the MD were more likely to be physically inactive $(p<0.0001$ and $p<0.01$, respectively), but did not report differences in sleep quality (Table 3 ).

Thirty percent of participants that reported changes in their eating habits compared to the period prior to the lockdown showed also high distress $(p<0.01)$ (Table 4$)$. This was especially evident in women, where $32 \%$ of women who claimed to have changed dietary habits presented with higher distress levels $(p<0.05)$ (Table 4$)$. 
Table 3. Distribution of responses for levels of adherence to the Mediterranean diet, physical activity, distress, and sleep quality in the total subjects and by sex.

\begin{tabular}{|c|c|c|c|c|c|c|c|c|c|c|c|c|c|c|c|}
\hline & \multicolumn{15}{|c|}{ Mediterranean Diet Adherence ${ }^{a}$} \\
\hline & \multicolumn{5}{|c|}{$\begin{array}{l}\text { Women } \\
n=433\end{array}$} & \multicolumn{5}{|c|}{$\begin{array}{c}\text { Men } \\
n=171\end{array}$} & \multicolumn{5}{|c|}{$\begin{array}{c}\text { Total } \\
n=604\end{array}$} \\
\hline & \multicolumn{2}{|c|}{ Low } & \multicolumn{2}{|c|}{ High } & \multirow[t]{2}{*}{$p^{*}$} & \multicolumn{2}{|c|}{ Low } & \multicolumn{2}{|c|}{ High } & \multirow[t]{2}{*}{$p^{*}$} & \multicolumn{2}{|c|}{ Low } & \multicolumn{2}{|c|}{ High } & \multirow[t]{2}{*}{$p^{*}$} \\
\hline & $n$ & $(\%)$ & $n$ & $(\%)$ & & $n$ & $(\%)$ & $n$ & $(\%)$ & & $n$ & $(\%)$ & $n$ & $(\%)$ & \\
\hline \multicolumn{16}{|c|}{ Self-reported dietary changes } \\
\hline No & 83 & 31.6 & 51 & 30.2 & 0.84 & 39 & 33.3 & 24 & 44.4 & 0.22 & 122 & 32.1 & 75 & 33.6 & 0.77 \\
\hline Yes & 180 & 68.4 & 118 & 69.8 & & 78 & 66.7 & 30 & 55.6 & & 258 & 67.9 & 148 & 66.4 & \\
\hline Total & 263 & 100.0 & 169 & 100.0 & & 117 & 100.0 & 54 & 100.0 & & 380 & 100.0 & 223 & 100.0 & \\
\hline \multicolumn{16}{|l|}{ Dietary changes } \\
\hline Reduced & 105 & 39.8 & 69 & 40.8 & 0.25 & 52 & 44.4 & 18 & 33.3 & $<0.01$ & 157 & 41.2 & 87 & 39.0 & 0.015 \\
\hline No change & 66 & 25.0 & 52 & 30.8 & & 20 & 17.1 & 21 & 38.9 & & 86 & 22.6 & 73 & 32.7 & \\
\hline Increased & 93 & 35.2 & 48 & 28.4 & & 45 & 38.5 & 15 & 27.8 & & 138 & 36.2 & 63 & 28.3 & \\
\hline Total & 264 & 100.0 & 169 & 100.0 & & 117 & 100.0 & 54 & 100.0 & & 381 & 100.0 & 223 & 100.0 & \\
\hline \multicolumn{16}{|l|}{ Physical activity ${ }^{b}$} \\
\hline Active & 41 & 15.5 & 40 & 23.7 & $<0.0001$ & 18 & 15.4 & 20 & 37.0 & $<0.01$ & 59 & 15.5 & 60 & 26.9 & $<0.0001$ \\
\hline Moderately active & 94 & 35.6 & 84 & 49.7 & & 49 & 41.9 & 21 & 38.9 & & 143 & 37.5 & 105 & 47.1 & \\
\hline Inactive & 129 & 48.9 & 45 & 26.6 & & 50 & 42.7 & 13 & 24.1 & & 179 & 47.0 & 58 & 26.0 & \\
\hline Total & 264 & 100.0 & 169 & 100.0 & & 117 & 100.0 & 54 & 100.0 & & 381 & 100.0 & 223 & 100.0 & \\
\hline \multicolumn{16}{|l|}{ Distress $^{c}$} \\
\hline Low & 78 & 29.5 & 46 & 27.2 & 0.84 & 59 & 50.4 & 33 & 61.1 & 0.32 & 137 & 36.0 & 79 & 35.4 & 0.79 \\
\hline Medium & 109 & 41.3 & 74 & 43.8 & & 30 & 25.6 & 13 & 24.1 & & 139 & 36.5 & 87 & 39.0 & \\
\hline High & 77 & 29.2 & 49 & 29.0 & & 28 & 23.9 & 8 & 14.8 & & 105 & 27.6 & 57 & 25.6 & \\
\hline Total & 264 & 100.0 & 169 & 100.0 & & 117 & 100.0 & 54 & 100.0 & & 381 & 100.0 & 223 & 100.0 & \\
\hline \multicolumn{16}{|l|}{ Sleep quality ${ }^{d}$} \\
\hline Low & 168 & 63.6 & 110 & 65.1 & 0.84 & 70 & 59.8 & 22 & 40.7 & $<0.05$ & 238 & 62.5 & 132 & 59.2 & 0.28 \\
\hline High & 96 & 36.4 & 59 & 34.9 & & 47 & 40.2 & 32 & 59.3 & & 143 & 37.5 & 91 & 40.8 & \\
\hline Total & 264 & 100.0 & 169 & 100.0 & & 117 & 100.0 & 54 & 100.0 & & 381 & 100.0 & 223 & 100.0 & \\
\hline
\end{tabular}

a Adherence to the Mediterranean diet: low adherence score $\leq 5$; high adherence score $>5$ (up to 9). ${ }^{b}$ Physical activity level: Inactive total METs $\leq 700$; Moderately active total METs $\geq 701 \leq 2519$; Active total METs $\geq 2520$. ${ }^{c}$ Distress level: no distress score $\leq 8$; Moderate distress score 9-16; distress score $\geq 17$. ${ }^{\mathrm{d}}$ Sleep quality level: low sleep quality score $>10$; high sleep quality score $\leq 10 .{ }^{*}$ Chi-square test. Bold data indicate statistically significant $p$-value $(p<0.05)$.

Table 4. Distribution of responses for self-reported dietary changes to physical activity, distress, and sleep quality in total subjects and by sex.

\begin{tabular}{|c|c|c|c|c|c|c|c|c|c|c|c|c|c|c|c|}
\hline & \multicolumn{15}{|c|}{ Self-Reported Dietary Changes } \\
\hline & \multicolumn{5}{|c|}{$\begin{array}{l}\text { Women } \\
n=433\end{array}$} & \multicolumn{5}{|c|}{$\begin{array}{c}\text { Men } \\
n=171\end{array}$} & \multicolumn{5}{|c|}{$\begin{array}{c}\text { Total } \\
n=604\end{array}$} \\
\hline & \multicolumn{2}{|c|}{ No } & \multicolumn{2}{|c|}{ Yes } & \multirow[t]{2}{*}{$p^{*}$} & \multicolumn{2}{|c|}{ No } & \multicolumn{2}{|c|}{ Yes } & \multirow[t]{2}{*}{$p^{*}$} & \multicolumn{2}{|c|}{ No } & \multicolumn{2}{|c|}{ Yes } & \multirow[t]{2}{*}{$p^{*}$} \\
\hline & $n$ & $(\%)$ & $n$ & $(\%)$ & & $n$ & $(\%)$ & $N$ & $(\%)$ & & $n$ & $(\%)$ & $n$ & $(\%)$ & \\
\hline \multicolumn{16}{|l|}{ Physical activity ${ }^{a}$} \\
\hline Active & 28 & 20.9 & 53 & 17.8 & 0.69 & 11 & 17.5 & 27 & 25.0 & 0.22 & 39 & 19.8 & 80 & 19.7 & 0.92 \\
\hline Moderately active & 52 & 38.8 & 126 & 42.3 & & 31 & 49.2 & 39 & 36.1 & & 83 & 42.1 & 165 & 40.6 & \\
\hline Inactive & 54 & 40.3 & 119 & 39.9 & & 21 & 33.3 & 42 & 38.9 & & 75 & 38.1 & 161 & 39.7 & \\
\hline Total & 134 & 100.0 & 298 & 100.0 & & 63 & 100.0 & 108 & 100.0 & & 197 & 100.0 & 406 & 100.0 & \\
\hline \multicolumn{16}{|l|}{ Distress $^{b}$} \\
\hline Low & 49 & 36.6 & 75 & 25.2 & $<0.05$ & 38 & 60.3 & 54 & 50.0 & 0.23 & 87 & 44.2 & 129 & 31.8 & $<0.01$ \\
\hline Medium & 54 & 40.3 & 128 & 43.0 & & 16 & 25.4 & 27 & 25.0 & & 70 & 35.5 & 155 & 38.2 & \\
\hline High & 31 & 23.1 & 95 & 31.9 & & 9 & 14.3 & 27 & 25.0 & & 40 & 20.3 & 122 & 30.0 & \\
\hline Total & 134 & 100.0 & 298 & 100.0 & & 63 & 100.0 & 108 & 100.0 & & 197 & 100.0 & 406 & 100.0 & \\
\hline \multicolumn{16}{|l|}{ Sleep quality ${ }^{c}$} \\
\hline Low & 80 & 59.7 & 198 & 66.4 & 0.21 & 32 & 50.8 & 60 & 55.6 & 0.65 & 112 & 56.9 & 258 & 63.5 & 0.13 \\
\hline High & 54 & 40.3 & 100 & 33.6 & & 31 & 49.2 & 48 & 44.4 & & 85 & 43.1 & 148 & 36.5 & \\
\hline Total & 134 & 100.0 & 298 & 100.0 & & 63 & 100.0 & 108 & 100.0 & & 197 & 100.0 & 406 & 100.0 & \\
\hline
\end{tabular}

a Physical activity level: Inactive total METs $\leq 700$; Moderately active total METs 701-2519; Active total METs $\geq 2520 .{ }^{\text {b }}$ Distress level: no distress score $\leq 8$; Moderate distress score 9-16; distress score $\geq 17$. ${ }^{c}$ Sleep quality level: low sleep quality score $>10$; high sleep quality score $\leq 10 .{ }^{*}$ Chi-square test. Bold data indicate statistically significant $p$-value $(p<0.05)$.

In Table 5 we reported physical activity levels by sleep quality and distress. In the overall sample we found that those who were physically active showed lower distress 
$(60 \% ; p<0.008)$. Among active men $87 \%$ reported low distress $(p<0.001)$ while this was not observed in women.

Table 5. Correlation between physical activity and sleep quality and distress in total subjects and by sex.

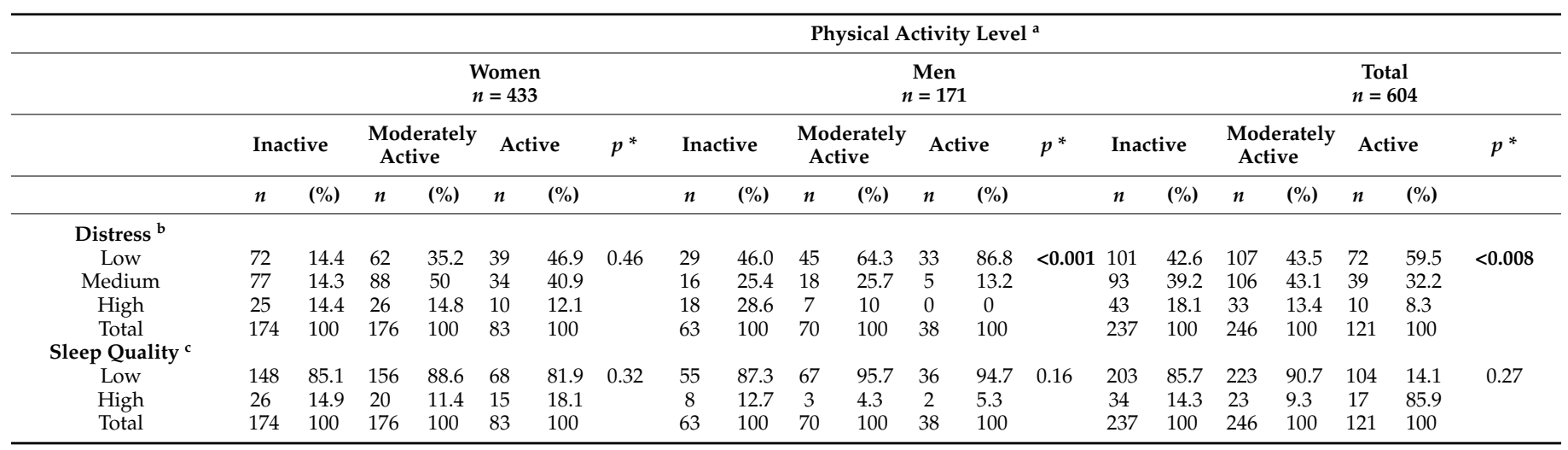

${ }^{a}$ Physical activity level: Inactive total METs $\leq 700$; Moderately active total METs 701-2519; Active total METs $\geq 2520$. ${ }^{\mathrm{b}}$ Distress level: no distress score $\leq 8$; Moderate distress score 9-16; distress score $\geq 17$. ${ }^{c}$ Sleep quality level: low sleep quality score $>10$; high sleep quality score $\leq 10 .{ }^{*}$ t-student test. Bold data indicate statistically significant $p$-value $(p<0.05)$.

Table 6 shows the results of the logistic regression analysis of PA level for low MedDiet adherence, where it emerged that subjects with low adherence to the MedDiet had three times higher risk of being physically inactive than those with higher adherence (OR: 3.1; 95\% CI: $1.9,5.0 ; p<0.0001$ ) (Table 6).

Table 6. Multivariate logistic regression analyses of Physical activity level for low Mediterranean diet adherence.

\begin{tabular}{|c|c|c|c|c|c|c|c|c|c|c|c|c|}
\hline & \multicolumn{12}{|c|}{ Low Mediterranean Diet Adherence ${ }^{a}$} \\
\hline & \multicolumn{4}{|c|}{$\begin{array}{l}\text { Women } \\
n=433\end{array}$} & \multicolumn{4}{|c|}{$\begin{array}{c}\text { Men } \\
n=171\end{array}$} & \multicolumn{4}{|c|}{$\begin{array}{c}\text { Total } \\
n=604\end{array}$} \\
\hline & \multirow[t]{3}{*}{$\mathrm{OR}^{\mathrm{b}}$} & \multicolumn{2}{|c|}{$95 \% \mathrm{CI}$} & \multirow[t]{3}{*}{$p^{\mathrm{c}}$} & \multirow[t]{3}{*}{$\mathrm{OR}^{\mathbf{b}}$} & \multicolumn{2}{|c|}{$95 \% \mathrm{CI}$} & \multirow[t]{3}{*}{$p^{c}$} & \multirow[t]{3}{*}{$\mathrm{OR}^{\mathrm{b}}$} & \multicolumn{2}{|c|}{$95 \%$ CI } & \multirow[t]{3}{*}{$p^{c}$} \\
\hline & & Lower & Upper & & & Lower & Upper & & & Lower & Upper & \\
\hline & & Limit & Limit & & & Limit & Limit & & & Limit & Limit & \\
\hline \multicolumn{13}{|l|}{ Physical activity ${ }^{d}$} \\
\hline Active & $1\left(\operatorname{Ref}^{\mathrm{e}}\right)$ & & & & 1(Ref) & & & & 1(Ref) & & & \\
\hline Moderately active & 2.50 & 1.59 & 3.92 & $<0.0001$ & 1.75 & 0.75 & 4.13 & 0.195 & 2.12 & 1.422 & 3.16 & $<0.0001$ \\
\hline Inactive & 2.93 & 1.69 & 5.11 & $<0.0001$ & 4.96 & 1.94 & 12.7 & 0.001 & 3.14 & 1.953 & 5.03 & $<0.0001$ \\
\hline
\end{tabular}

${ }^{a}$ Adherence to the Mediterranean diet: low adherence score $\leq 5$; high adherence score $>5 .{ }^{\mathbf{b}}$ OR= Odds Ratio adjusted for terms of age ( $\leq 25 ; 26-35 ; \geq 36)$; occupation (students; workers; other); region of residence (Campania; Center-North; South-Islands); gender. ${ }^{\mathbf{c}}$ Chi-square. ${ }^{\mathrm{d}}$ Physical activity level: Inactive total METs $\leq 700$; Moderately active total METs 701-2519; Active total METs $\geq 2520$. ${ }^{\mathrm{e}}$ Ref $=$ Reference category. Bold data indicate statistically significant $p$-value $(p<0.05)$.

\section{Discussion}

This study is the first study that simultaneously analyzes adherence to the MedDiet, PA, quality of sleep and distress levels within a young Italian cohort during the COVID19 induced lockdown. Results indicate that dietary and lifestyle habits were negatively impacted during the lockdown. More specifically, $63 \%$ of study participants showed low adherence to the MedDiet and $67 \%$ reported changes in their eating habits compared to the period prior to the lockdown. Specifically, there was a significant increase in the intake of foods containing added sugars and saturated fats amongst $51 \%$ of subjects. In addition, subjects with low adherence to the MedDiet showed three times greater risk of being physically inactive than those with higher adherence.

It is important to consider that in recent years the populations of the Mediterranean basin (including the Italian population) have made a slow and progressive move away from the traditional Mediterranean dietary pattern to embrace an increasingly Westernized 
diet. Before the COVID-19 lockdown, eating habits in the Mediterranean basin were characterized by an increasing consumption of red and processed meats, sweet drinks and refined cereals, a dietary pattern associated with an increased risk of disease [24,25]. In studies carried out via online surveys in Italy, Croatia, Spain, Chile, Colombia, and Brazil in the same period $[6,10,11]$ showed that improved adherence to the MedDiet (or its modified version) was found in young adults. This age group, unlike younger or older people, however, tends to eat outside the home frequently; hence, home confinement induced higher frequency of home cooking, which is linked to healthier dietary habits [11].

In terms of physical activity both women and men with a low adherence to the MedDiet were more likely to be physically inactive. In those doing lower levels of physical activity, a higher level of distress was reported. Moreover, most participants reported to have poorer sleep quality when compared to the pre-lockdown period. The MedDiet, characterized by a frequent intake of olive oil, fruit, vegetables, wholegrains, legumes, fish, nuts, and a low intake of processed meat and added sugars is frequently associated with reduced risk of chronic diseases such as cancer, type 2 diabetes, and cardiovascular disease [26-29]. The MedDiet score has also been shown to be inversely associated with anxiety and depression amongst adults [30]. A reduction in adherence to the MedDiet would therefore have multiple negative consequences on both physical and mental wellbeing. Firstly, on the level of immune health, it is well established that a diet rich in vitamins and minerals play an integral role in supporting the immune system $[18,26,31]$ Vitamins A, D, E, and zinc in particular have been implied in lower susceptibility to infections and in modulating the immune response $[17,26,32-36]$. In addition, vegetables, fruit, legumes, nuts, and olive oil are rich in antioxidants, which are linked to having anti-inflammatory and anti-viral activity $[34,35,37,38]$. The isothiocyanates present in cruciferous vegetables (abundant in the MedDiet) are involved in the inhibition of NF- $\mathrm{KB}$, an important mediator of the inflammatory process $[39,40]$ which can be relevant in COVID-19 where high inflammatory levels have been reported [18,41].

Secondly, a lower adherence to the MedDiet as well as higher consumption of foods high in added sugar and saturated fat imply an increase in overall caloric intake. Higher energy intakes coupled with lower physical activity have been associated with increased total body fat, and particularly abdominal fat possibly driven by insulin resistance and increased circulating inflammatory cytokines [42,43]. It has been shown that metabolic status (e.g., obesity), age and sex influence the clinical severity of COVID-19 [44]. A diet high in refined carbohydrates has been shown to increase the production of pro-inflammatory cytokines [45] and high intakes of saturated fatty acids have been associated with increased corticosterone levels and increased circulating inflammatory cytokines [46]. The MedDiet however has anti-inflammatory effects [47-49]. Adequate control of inflammatory markers could be important to reduce the risk of severe COVID-19 [18,47-49]. For its anti-inflammatory and immunomodulatory effects, several studies recommend this dietary model as a potential dietary approach during COVID-19 health emergency [50,51].

Previous research indicated that an inverse association between adherence to the MedDiet and likelihood of psychological disorders including depression, anxiety, and psychological distress exists and our results support this [52]. Our findings indicate that women were more likely to report higher levels than their male counterparts. These results are in line with other studies that have found that women were more likely to report psychological distress and anxiety during lockdown [53-55].

Another core pillar of physical and mental wellbeing is physical activity [56]. Thirtynine percent of the participants in our study were inactive, and as many as $76 \%$ reported changes in their PA level by becoming more sedentary, which is plausible given the mandatory home confinement. In similar studies, an increase in sitting time $[57,58]$ and a reduction in the time spent on physical activity have also been reported [57]. A survey in Italian university students [59] and a study in the general population [60] both using IPAQ, found an overall reduction in PA (moderate and vigorous) and a significant increase in sedentary behavior during COVID-19 lockdown. 
In addition, a study on global step count before and during COVID-19 supports our findings [61]. Physical Activity Guidelines for Italians recommends for adults to do at least 120 to $300 \mathrm{~min}$ per week of moderate PA, or 75 to $150 \mathrm{~min}$ per week of vigorous PA, or a combination of these. Aerobic activity should be well distributed throughout the week. PA can alleviate oxidative stress, reduce inflammation, support a healthy immune system and is known to reduce the risk of chronic diseases such as cardiovascular disease and type 2 diabetes [62-65]. In addition, moderate and vigorous PA has been linked to a reduction in psychological distress, increase feeling of well-being, improved sleep $[66,67]$ and possibly also lead to better adherence to the MedDiet $[58,68,69]$. These factors may concur to help people feel better and could be important to reduce the risk of severe COVID19 [70]. During the COVID-19 pandemic, several studies have evaluated the impact of lockdown on many aspects of lifestyle. [3,7,71,72]. In line with our studies, collective findings indicate that eating habits, sleep quality, physical activity levels, and general wellbeing were negatively impacted during the wide-scale self-isolation period [4,6]. A recent study showed a dose-dependent increase in the risk of COVID-19 in subjects who exhibited a less healthy lifestyle, compared to people who adopted a healthy lifestyle. This appears to be related to a low-grade inflammatory state as well as a higher risk of non-communicable diseases [70]. Other research has indicated that $94 \%$ of hospitalized COVID-19 patients who have died had at least one obesity-associated comorbidity such as diabetes, hypertension, cardiovascular disease, chronic lung disease, or certain cancers [73]. In the context of COVID-19 therefore, promoting a healthy lifestyle, both in terms of diet and physical exercise is pivotal. Unhealthy lifestyle is considered a risk factor for COVID-19 hospitalization [70].

However, studies conducted in different countries showed that eating habits and PA during lockdown can be influenced by age, by type of occupation, and by different family habits (e.g., eating at home versus eating out at lunch breaks), therefore comparing study results requires attention towards the comparator group and cultural differences. Other incongruencies between study results may depend on the country-specific anti-COVID-19 restrictions imposed by local governments, e.g., in Switzerland there were no restrictions for outdoors PA and sports $[6,74,75]$. Furthermore, adherence to the MedDiet may also change between Italian regions, as it is generally higher in the southern than in the northern regions of Italy [76].

Findings herein must be considered in the framework of the study limitations. The data is cross sectional, and hence associations between diet quality, physical activity level and levels of distress are correlational only. The recruitment method (i.e., social media platforms including Facebook, WhatsApp, and Instagram) led to a selective proportion of the Italian population being sampled. Another limitation is the recall-bias due to the conduct of the investigation during a difficult period that could have created alterations in one's perceptions compared to the period prior to the lockdown.

\section{Conclusions}

This is the first study to evaluate the different lifestyle components together (diet, physical activity, distress, and sleep quality) in a young Italian population during COVID19 lockdown.

Our results show that during large-scale self-isolation to control a pandemic, low adherence to the MedDiet among young Italians is associated with a lower level of physical activity and a higher level of distress, suggesting that prolonged confinement promotes unhealthy lifestyle changes which in the long term could have a negative impact on public health and complications related to COVID-19. Although causality cannot be inferred, isolation does not seem to help maintain a healthy lifestyle. We would like to highlight the importance of taking preventive measures and suggest public health programs to promote healthy diets, physical activity, and stress management during future mass lockdowns.

Supplementary Materials: The following are available on line at: https:/ / www.mdpi.com/article / 10.3390 / nu13061923/s1, Table S1. Details of the survey. 
Author Contributions: Conceptualization, M.P., L.S.A.A.; Methodology, M.P., G.B., L.S.A.A.; Validation, L.S.A.A., A.C., C.L.V.; Formal Analysis, C.M., A.C., S.C., M.P.; Investigation, M.P., G.B., A.L.; Data Curation, M.P., C.M.; Writing-Original Draft Preparation, M.P., L.S.A.A., L.P.; Writing-Review \& Editing, M.P., L.P., A.L., G.B., C.L.V., C.M., S.C., L.S.A.A., I.C., S.V., E.P., G.P., A.C., E.C.; Visualization, M.P., C.L.V., L.S.A.A., A.C.; Supervision, C.L.V., L.S.A.A., A.C. All authors have read and agreed to the published version of the manuscript.

Funding: This research received no external funding.

Institutional Review Board Statement: Ethical review and approval were waived for this study, due to the nature of the study (online survey) and that data were anonymously collected on a voluntary basis.

Informed Consent Statement: Subject consent was waived due to the nature of the study (online survey) and that data were anonymously collected on a voluntary basis.

Data Availability Statement: The data presented in this study are available on request from the corresponding author. The data are not publicly available due to ethical restrictions.

Conflicts of Interest: The authors declare no conflict of interest.

\section{References}

1. Wang, Y.; Shi, L.; Que, J.; Lu, Q.; Liu, L.; Lu, Z.; Xu, Y.; Liu, J.; Sun, Y.; Meng, S.; et al. The impact of quarantine on mental health status among general population in China during the COVID-19 pandemic. Mol. Psychiatry 2021. [CrossRef]

2. Clemente-Suarez, V.J.; Dalamitros, A.A.; Beltran-Velasco, A.I.; Mielgo-Ayuso, J.; Tornero-Aguilera, J.F. Social and Psychophysiological Consequences of the COVID-19 Pandemic: An Extensive Literature Review. Front. Psychol. 2020, 11, 580225. [CrossRef]

3. Zhang, S.X.; Wang, Y.; Rauch, A.; Wei, F. Unprecedented disruption of lives and work: Health, distress and life satisfaction of working adults in China one month into the COVID-19 outbreak. Psychiatry Res. 2020, 288, 112958. [CrossRef]

4. Rodriguez-Perez, C.; Molina-Montes, E.; Verardo, V.; Artacho, R.; Garcia-Villanova, B.; Guerra-Hernandez, E.J.; Ruiz-Lopez, M.D. Changes in Dietary Behaviours during the COVID-19 Outbreak Confinement in the Spanish COVIDiet Study. Nutrients 2020, 12, 1730. [CrossRef] [PubMed]

5. Lamarche, B.; Brassard, D.; Lapointe, A.; Laramee, C.; Kearney, M.; Cote, M.; Belanger-Gravel, A.; Desroches, S.; Lemieux, S.; Plante, C. Changes in diet quality and food security among adults during the COVID-19-related early lockdown: Results from NutriQuebec. Am. J. Clin. Nutr. 2021, 113, 984-992. [CrossRef] [PubMed]

6. Di Renzo, L.; Gualtieri, P.; Pivari, F.; Soldati, L.; Attina, A.; Cinelli, G.; Leggeri, C.; Caparello, G.; Barrea, L.; Scerbo, F.; et al. Eating habits and lifestyle changes during COVID-19 lockdown: An Italian survey. J. Transl. Med. 2020, 18, 229. [CrossRef]

7. Lopez-Bueno, R.; Calatayud, J.; Casana, J.; Casajus, J.A.; Smith, L.; Tully, M.A.; Andersen, L.L.; Lopez-Sanchez, G.F. COVID-19 Confinement and Health Risk Behaviors in Spain. Front. Psychol. 2020, 11, 1426. [CrossRef] [PubMed]

8. Izzo, L.; Santonastaso, A.; Cotticelli, G.; Federico, A.; Pacifico, S.; Castaldo, L.; Colao, A.; Ritieni, A. An Italian Survey on Dietary Habits and Changes during the COVID-19 Lockdown. Nutrients 2021, 13, 1197. [CrossRef]

9. Fuzeki, E.; Schroder, J.; Carraro, N.; Merlo, L.; Reer, R.; Groneberg, D.A.; Banzer, W. Physical Activity during the First COVID-19Related Lockdown in Italy. Int. J. Environ. Res. Public Health 2021, 18, 2511. [CrossRef]

10. Ruiz-Roso, M.B.; de Carvalho Padilha, P.; Mantilla-Escalante, D.C.; Ulloa, N.; Brun, P.; Acevedo-Correa, D.; Arantes Ferreira Peres, W.; Martorell, M.; Aires, M.T.; de Oliveira Cardoso, L.; et al. Covid-19 Confinement and Changes of Adolescent's Dietary Trends in Italy, Spain, Chile, Colombia and Brazil. Nutrients 2020, 12, 1807. [CrossRef]

11. Pfeifer, D.; Resetar, J.; Gajdos Kljusuric, J.; Panjkota Krbavcic, I.; Vranesic Bender, D.; Rodriguez-Perez, C.; Ruiz-Lopez, M.D.; Satalic, Z. Cooking at Home and Adherence to the Mediterranean Diet During the COVID-19 Confinement: The Experience from the Croatian COVIDiet Study. Front. Nutr. 2021, 8, 617721. [CrossRef] [PubMed]

12. Koball, A.M.; Meers, M.R.; Storfer-Isser, A.; Domoff, S.E.; Musher-Eizenman, D.R. Eating when bored: Revision of the emotional eating scale with a focus on boredom. Health Psychol. Off. J. Div. Health Psychol. Am. Psychol. Assoc. 2012, 31, 521-524. [CrossRef]

13. Yannakoulia, M.; Panagiotakos, D.B.; Pitsavos, C.; Tsetsekou, E.; Fappa, E.; Papageorgiou, C.; Stefanadis, C. Eating habits in relations to anxiety symptoms among apparently healthy adults. A pattern analysis from the ATTICA Study. Appetite 2008, 51, 519-525. [CrossRef]

14. Moynihan, A.B.; van Tilburg, W.A.; Igou, E.R.; Wisman, A.; Donnelly, A.E.; Mulcaire, J.B. Eaten up by boredom: Consuming food to escape awareness of the bored self. Front. Psychol. 2015, 6, 369. [CrossRef]

15. Montemurro, N. The emotional impact of COVID-19: From medical staff to common people. Brain Behav. Immun. 2020, 87, 23-24. [CrossRef] [PubMed]

16. Lima, C.K.T.; Carvalho, P.M.M.; Lima, I.; Nunes, J.; Saraiva, J.S.; de Souza, R.I.; da Silva, C.G.L.; Neto, M.L.R. The emotional impact of Coronavirus 2019-nCoV (new Coronavirus disease). Psychiatry Res. 2020, 287, 112915. [CrossRef] [PubMed] 
17. Detopoulou, P.; Demopoulos, C.A.; Antonopoulou, S. Micronutrients, Phytochemicals and Mediterranean Diet: A Potential Protective Role against COVID-19 through Modulation of PAF Actions and Metabolism. Nutrients 2021, 13, 462. [CrossRef] [PubMed]

18. Jayawardena, R.; Sooriyaarachchi, P.; Chourdakis, M.; Jeewandara, C.; Ranasinghe, P. Enhancing immunity in viral infections, with special emphasis on COVID-19: A review. Diabetes Metab. Syndr. 2020, 14, 367-382. [CrossRef] [PubMed]

19. Gnagnarella, P.; Draga, D.; Misotti, A.M.; Sieri, S.; Spaggiari, L.; Cassano, E.; Baldini, F.; Soldati, L.; Maisonneuve, P. Validation of a short questionnaire to record adherence to the Mediterranean diet: An Italian experience. Nutr. Metab. Cardiovasc. Dis. NMCD 2018, 28, 1140-1147. [CrossRef]

20. Trichopoulou, A.; Bamia, C.; Lagiou, P.; Trichopoulos, D. Conformity to traditional Mediterranean diet and breast cancer risk in the Greek EPIC (European Prospective Investigation into Cancer and Nutrition) cohort. Am. J. Clin. Nutr. 2010, 92, 620-625. [CrossRef]

21. Hagstromer, M.; Oja, P.; Sjostrom, M. The International Physical Activity Questionnaire (IPAQ): A study of concurrent and construct validity. Public Health Nutr. 2006, 9, 755-762. [CrossRef] [PubMed]

22. Kessler, R.C.; Andrews, G.; Colpe, L.J.; Hiripi, E.; Mroczek, D.K.; Normand, S.L.; Walters, E.E.; Zaslavsky, A.M. Short screening scales to monitor population prevalences and trends in non-specific psychological distress. Psychol. Med. 2002, 32, 959-976. [CrossRef] [PubMed]

23. Buysse, D.J.; Reynolds, C.F., 3rd; Monk, T.H.; Berman, S.R.; Kupfer, D.J. The Pittsburgh Sleep Quality Index: A new instrument for psychiatric practice and research. Psychiatry Res. 1989, 28, 193-213. [CrossRef]

24. Kopp, W. How Western Diet And Lifestyle Drive The Pandemic Of Obesity And Civilization Diseases. Diabetes Metab. Syndr. Obes. Targets Ther. 2019, 12, 2221-2236. [CrossRef] [PubMed]

25. Alberti-Fidanza, A.; Fidanza, F. Mediterranean Adequacy Index of Italian diets. Public Health Nutr. 2004, 7, 937-941. [CrossRef]

26. Scrimshaw, N.S.; SanGiovanni, J.P. Synergism of nutrition, infection, and immunity: An overview. Am. J. Clin. Nutr. 1997, 66, 464S-477S. [CrossRef]

27. Kontou, N.; Psaltopoulou, T.; Panagiotakos, D.; Dimopoulos, M.A.; Linos, A. The mediterranean diet in cancer prevention: A review. J. Med. Food 2011, 14, 1065-1078. [CrossRef]

28. De Lorgeril, M. PREDIMED trial: Mediterranean diet may reduce the risk of type 2 diabetes. Evid. Based Med. 2011, 16, 152-153. [CrossRef]

29. Sofi, F.; Macchi, C.; Abbate, R.; Gensini, G.F.; Casini, A. Mediterranean diet and health status: An updated meta-analysis and a proposal for a literature-based adherence score. Public Health Nutr. 2014, 17, 2769-2782. [CrossRef]

30. Sanchez-Villegas, A.; Cabrera-Suarez, B.; Molero, P.; Gonzalez-Pinto, A.; Chiclana-Actis, C.; Cabrera, C.; Lahortiga-Ramos, F.; Florido-Rodriguez, M.; Vega-Perez, P.; Vega-Perez, R.; et al. Preventing the recurrence of depression with a Mediterranean diet supplemented with extra-virgin olive oil. The PREDI-DEP trial: Study protocol. BMC Psychiatry 2019, 19, 63. [CrossRef]

31. Vazquez-Calvo, A.; Jimenez de Oya, N.; Martin-Acebes, M.A.; Garcia-Moruno, E.; Saiz, J.C. Antiviral Properties of the Natural Polyphenols Delphinidin and Epigallocatechin Gallate against the Flaviviruses West Nile Virus, Zika Virus, and Dengue Virus. Front. Microbiol. 2017, 8, 1314. [CrossRef]

32. Villamor, E.; Fawzi, W.W. Effects of vitamin a supplementation on immune responses and correlation with clinical outcomes. Clin. Microbiol. Rev. 2005, 18, 446-464. [CrossRef]

33. Hewison, M. An update on vitamin D and human immunity. Clin. Endocrinol. 2012, 76, 315-325. [CrossRef] [PubMed]

34. Meydani, S.N.; Beharka, A.A. Recent developments in vitamin E and immune response. Nutr. Rev. 1998, 56, S49-S58. [CrossRef] [PubMed]

35. Meydani, S.N.; Han, S.N.; Wu, D. Vitamin E and immune response in the aged: Molecular mechanisms and clinical implications. Immunol. Rev. 2005, 205, 269-284. [CrossRef]

36. Pecora, F.; Persico, F.; Argentiero, A.; Neglia, C.; Esposito, S. The Role of Micronutrients in Support of the Immune Response against Viral Infections. Nutrients 2020, 12, 3198. [CrossRef] [PubMed]

37. Cheng, Y.C.; Sheen, J.M.; Hu, W.L.; Hung, Y.C. Polyphenols and Oxidative Stress in Atherosclerosis-Related Ischemic Heart Disease and Stroke. Oxidative Med. Cell. Longev. 2017, 2017, 8526438. [CrossRef] [PubMed]

38. Serino, A.; Salazar, G. Protective Role of Polyphenols against Vascular Inflammation, Aging and Cardiovascular Disease. Nutrients 2018, 11, 53. [CrossRef] [PubMed]

39. Navarro, S.L.; Li, F.; Lampe, J.W. Mechanisms of action of isothiocyanates in cancer chemoprevention: An update. Food Funct. 2011, 2, 579-587. [CrossRef]

40. Talalay, P.; Fahey, J.W. Phytochemicals from cruciferous plants protect against cancer by modulating carcinogen metabolism. J. Nutr. 2001, 131, 3027S-3033S. [CrossRef]

41. Jasso-Miranda, C.; Herrera-Camacho, I.; Flores-Mendoza, L.K.; Dominguez, F.; Vallejo-Ruiz, V.; Sanchez-Burgos, G.G.; PandoRobles, V.; Santos-Lopez, G.; Reyes-Leyva, J. Antiviral and immunomodulatory effects of polyphenols on macrophages infected with dengue virus serotypes 2 and 3 enhanced or not with antibodies. Infect. Drug Resist. 2019, 12, 1833-1852. [CrossRef]

42. Bowden Davies, K.A.; Sprung, V.S.; Norman, J.A.; Thompson, A.; Mitchell, K.L.; Halford, J.C.G.; Harrold, J.A.; Wilding, J.P.H.; Kemp, G.J.; Cuthbertson, D.J. Short-term decreased physical activity with increased sedentary behaviour causes metabolic derangements and altered body composition: Effects in individuals with and without a first-degree relative with type 2 diabetes. Diabetologia 2018, 61, 1282-1294. [CrossRef] 
43. De Luca, C.; Olefsky, J.M. Inflammation and insulin resistance. FEBS Lett. 2008, 582, 97-105. [CrossRef]

44. Weiss, P.; Murdoch, D.R. Clinical course and mortality risk of severe COVID-19. Lancet 2020, 395, 1014-1015. [CrossRef]

45. Giugliano, D.; Ceriello, A.; Esposito, K. The effects of diet on inflammation: Emphasis on the metabolic syndrome. J. Am. Coll. Cardiol. 2006, 48, 677-685. [CrossRef]

46. Tan, B.L.; Norhaizan, M.E. Effect of High-Fat Diets on Oxidative Stress, Cellular Inflammatory Response and Cognitive Function. Nutrients 2019, 11, 2579. [CrossRef] [PubMed]

47. Casas, R.; Sacanella, E.; Estruch, R. The immune protective effect of the Mediterranean diet against chronic low-grade inflammatory diseases. Endocr. Metab. Immune Disord. Drug Targets 2014, 14, 245-254. [CrossRef] [PubMed]

48. Casas, R.; Estruch, R.; Sacanella, E. The Protective Effects of Extra Virgin Olive Oil on Immune-mediated Inflammatory Responses. Endocr. Metab. Immune Disord. Drug Targets 2018, 18, 23-35. [CrossRef] [PubMed]

49. Estruch, R. Anti-inflammatory effects of the Mediterranean diet: The experience of the PREDIMED study. Proc. Nutr. Soc. 2010, 69, 333-340. [CrossRef]

50. Angelidi, A.M.; Kokkinos, A.; Katechaki, E.; Ros, E.; Mantzoros, C.S. Mediterranean diet as a nutritional approach for COVID-19. Metab. Clin. Exp. 2021, 114, 154407. [CrossRef]

51. Maiorino, M.I.; Bellastella, G.; Longo, M.; Caruso, P.; Esposito, K. Mediterranean Diet and COVID-19: Hypothesizing Potential Benefits in People with Diabetes. Front. Endocrinol. 2020, 11, 574315. [CrossRef]

52. Sadeghi, O.; Keshteli, A.H.; Afshar, H.; Esmaillzadeh, A.; Adibi, P. Adherence to Mediterranean dietary pattern is inversely associated with depression, anxiety and psychological distress. Nutr. Neurosci. 2019, 1-12. [CrossRef] [PubMed]

53. Mazza, C.; Ricci, E.; Biondi, S.; Colasanti, M.; Ferracuti, S.; Napoli, C.; Roma, P. A Nationwide Survey of Psychological Distress among Italian People during the COVID-19 Pandemic: Immediate Psychological Responses and Associated Factors. Int. J. Environ. Res. Public Health 2020, 17, 3165. [CrossRef]

54. Gonzalez-Sanguino, C.; Ausin, B.; Castellanos, M.A.; Saiz, J.; Lopez-Gomez, A.; Ugidos, C.; Munoz, M. Mental health consequences during the initial stage of the 2020 Coronavirus pandemic (COVID-19) in Spain. Brain Behav. Immun. 2020, 87, 172-176. [CrossRef] [PubMed]

55. Gualano, M.R.; Lo Moro, G.; Voglino, G.; Bert, F.; Siliquini, R. Effects of Covid-19 Lockdown on Mental Health and Sleep Disturbances in Italy. Int. J. Environ. Res. Public Health 2020, 17, 4779. [CrossRef]

56. Warburton, D.E.; Nicol, C.W.; Bredin, S.S. Health benefits of physical activity: The evidence. CMAJ Can. Med. Assoc. J. J. Assoc. Med Can. 2006, 174, 801-809. [CrossRef] [PubMed]

57. Ammar, A.; Brach, M.; Trabelsi, K.; Chtourou, H.; Boukhris, O.; Masmoudi, L.; Bouaziz, B.; Bentlage, E.; How, D.; Ahmed, M.; et al. Effects of COVID-19 Home Confinement on Eating Behaviour and Physical Activity: Results of the ECLB-COVID19 International Online Survey. Nutrients 2020, 12, 1583. [CrossRef] [PubMed]

58. Romero-Blanco, C.; Rodriguez-Almagro, J.; Onieva-Zafra, M.D.; Parra-Fernandez, M.L.; Prado-Laguna, M.D.C.; HernandezMartinez, A. Physical Activity and Sedentary Lifestyle in University Students: Changes during Confinement Due to the COVID-19 Pandemic. Int. J. Environ. Res. Public Health 2020, 17, 6567. [CrossRef]

59. Galle, F.; Sabella, E.A.; Ferracuti, S.; de Giglio, O.; Caggiano, G.; Protano, C.; Valeriani, F.; Parisi, E.A.; Valerio, G.; Liguori, G.; et al. Sedentary Behaviors and Physical Activity of Italian Undergraduate Students during Lockdown at the Time of CoViD-19 Pandemic. Int. J. Environ. Res. Public Health 2020, 17, 6171. [CrossRef] [PubMed]

60. Maugeri, G.; Castrogiovanni, P.; Battaglia, G.; Pippi, R.; D’Agata, V.; Palma, A.; Di Rosa, M.; Musumeci, G. The impact of physical activity on psychological health during Covid-19 pandemic in Italy. Heliyon 2020, 6, e04315. [CrossRef]

61. Tison, G.H.; Avram, R.; Kuhar, P.; Abreau, S.; Marcus, G.M.; Pletcher, M.J.; Olgin, J.E. Worldwide Effect of COVID-19 on Physical Activity: A Descriptive Study. Ann. Intern. Med. 2020. [CrossRef] [PubMed]

62. Lee, J.Y.; Ryu, S.; Cheong, E.; Sung, K.C. Association of Physical Activity and Inflammation with All-Cause, CardiovascularRelated, and Cancer-Related Mortality. Mayo Clin. Proc. 2016, 91, 1706-1716. [CrossRef]

63. Da Silveira, M.P.; da Silva Fagundes, K.K.; Bizuti, M.R.; Starck, E.; Rossi, R.C.; de Resende, E.S.D.T. Physical exercise as a tool to help the immune system against COVID-19: An integrative review of the current literature. Clin. Exp. Med. 2020. [CrossRef] [PubMed]

64. Pedersen, B.K.; Hoffman-Goetz, L. Exercise and the immune system: Regulation, integration, and adaptation. Physiol. Rev. 2000, 80, 1055-1081. [CrossRef]

65. Piercy, K.L.; Troiano, R.P.; Ballard, R.M.; Carlson, S.A.; Fulton, J.E.; Galuska, D.A.; George, S.M.; Olson, R.D. The Physical Activity Guidelines for Americans. Jama 2018, 320, 2020-2028. [CrossRef]

66. Perales, F.; Pozo-Cruz, J.D.; Pozo-Cruz, B.D. Impact of physical activity on psychological distress: A prospective analysis of an Australian national sample. Am. J. Public Health 2014, 104, e91-e97. [CrossRef]

67. Kredlow, M.A.; Capozzoli, M.C.; Hearon, B.A.; Calkins, A.W.; Otto, M.W. The effects of physical activity on sleep: A meta-analytic review. J. Behav. Med. 2015, 38, 427-449. [CrossRef]

68. Matta, J.; Hoertel, N.; Kesse-Guyot, E.; Plesz, M.; Wiernik, E.; Carette, C.; Czernichow, S.; Limosin, F.; Goldberg, M.; Zins, M.; et al. Diet and physical activity in the association between depression and metabolic syndrome: Constances study. J. Affect. Disord. 2019, 244, 25-32. [CrossRef] [PubMed]

69. Gibson-Smith, D.; Bot, M.; Brouwer, I.A.; Visser, M.; Giltay, E.J.; Penninx, B. Association of food groups with depression and anxiety disorders. Eur. J. Nutr. 2020, 59, 767-778. [CrossRef] 
70. Hamer, M.; Kivimaki, M.; Gale, C.R.; Batty, G.D. Lifestyle risk factors, inflammatory mechanisms, and COVID-19 hospitalization: A community-based cohort study of 387,109 adults in UK. Brain Behav. Immun. 2020, 87, 184-187. [CrossRef]

71. Pietrobelli, A.; Pecoraro, L.; Ferruzzi, A.; Heo, M.; Faith, M.; Zoller, T.; Antoniazzi, F.; Piacentini, G.; Fearnbach, S.N.; Heymsfield S.B. Effects of COVID-19 Lockdown on Lifestyle Behaviors in Children with Obesity Living in Verona, Italy: A Longitudinal Study. Obesity 2020. [CrossRef] [PubMed]

72. Li, S.; Wang, Y.; Xue, J.; Zhao, N.; Zhu, T. The Impact of COVID-19 Epidemic Declaration on Psychological Consequences: A Study on Active Weibo Users. Int. J. Environ. Res. Public Health 2020, 17, 2032. [CrossRef] [PubMed]

73. Moser, J.S.; Galindo-Fraga, A.; Ortiz-Hernandez, A.A.; Gu, W.; Hunsberger, S.; Galan-Herrera, J.F.; Guerrero, M.L.; Ruiz-Palacios, G.M.; Beigel, J.H.; La Red, I.L.I.S.G. Underweight, overweight, and obesity as independent risk factors for hospitalization in adults and children from influenza and other respiratory viruses. Influenza Other Respir. Viruses 2019, 13, 3-9. [CrossRef] [PubMed]

74. Taeymans, J.; Luijckx, E.; Rogan, S.; Haas, K.; Baur, H. Physical Activity, Nutritional Habits, and Sleeping Behavior in Students and Employees of a Swiss University During the COVID-19 Lockdown Period: Questionnaire Survey Study. JMIR Public Health Surveill. 2021, 7, e26330. [CrossRef] [PubMed]

75. Barkley, J.E.; Lepp, A.; Glickman, E.; Farnell, G.; Beiting, J.; Wiet, R.; Dowdell, B. The Acute Effects of the COVID-19 Pandemic on Physical Activity and Sedentary Behavior in University Students and Employees. Int. J. Exerc. Sci. 2020, 13, 1326-1339.

76. Pelucchi, C.; Galeone, C.; Negri, E.; La Vecchia, C. Trends in adherence to the Mediterranean diet in an Italian population between 1991 and 2006. Eur. J. Clin. Nutr. 2010, 64, 1052-1056. [CrossRef] 